\title{
NOx Emissions from Euro 5 and Euro 6 Heavy-Duty Diesel Vehicles under Real Driving Conditions
}

\author{
Sangchul Ko ${ }^{1,2}$, Junhong Park ${ }^{1, *}$, Hyungjun Kim ${ }^{1}$, Gunwoo Kang ${ }^{1}$, Jongchul Lee ${ }^{1}$, \\ Jongmin Kim ${ }^{1}$ and Jongtae Lee ${ }^{1}$ \\ 1 National Institute of Environmental Research (NIER), Incheon 22689, Korea; scko@korea.kr (S.K.); \\ junandjin@korea.kr (H.K.); rjsnskfk@korea.kr (G.K.); jong07@korea.kr (J.L.); jmk8248@korea.kr (J.K.); \\ leelee@korea.kr (J.L.) \\ 2 Department of Construction Machinery Engineering, Inha University, Incheon 22212, Korea \\ * Correspondence: pjhy98@korea.kr; Tel.: +82-032-560-7625
}

Received: 12 November 2019; Accepted: 27 December 2019; Published: 2 January 2020

\begin{abstract}
Despite the strengthening of vehicle emissions standards and test methods, nitrogen oxide (NOx) emissions from on-road mobile sources are not being notably reduced. The introduction of real driving emission (RDE) regulations is expected to reduce the discrepancy between emission regulations and actual air pollution. To analyze the effects of RDE regulations on heavy-duty diesel vehicles, pollutants emitted while driving were measured using a portable emission measurement system (PEMS) for Euro 5 and Euro 6 vehicles, which were produced before and after RDE regulations, respectively. NOx emissions were compared as a function of emissions allowance standards, gross vehicle weight (GVW), average vehicle speed, and ambient temperature. NOx emissions from Euro 6 vehicles were found to be low, regardless of GVW; emissions from both vehicular categories increased with a decline in the average speed. To reflect real road driving characteristics more broadly in the RDE test method for heavy-duty vehicles, it is necessary to consider engine power, which is a criterion for classifying effective sections, in the moving average window (MAW) analysis method, as well as including cold start conditions.
\end{abstract}

Keywords: NOx; heavy-duty diesel vehicles; vehicle emissions standards; real driving emissions; in-service conformity; portable emission measurement system

\section{Introduction}

Emission allowance standards and test methods for vehicles are continuously being strengthened to reduce the air pollutants emitted from diesel vehicles [1]. The Euro 6 standards have tightened the limits for particulate matter and nitrogen oxide (NOx) by approximately $90 \%$ from the Euro 3 standards; however, they have not contributed to the improvement of air pollution in large cities as much as expected. The $\mathrm{PM}_{10}$ concentration in Seoul is more than twice that of Tokyo and London, and the $\mathrm{PM}_{2.5}$ concentration is more than double the World Health Organization's (WHO's) recommendation [2]. The $\mathrm{PM}_{10}$ concentration in Seoul has been continuously decreasing since 2001, but the $\mathrm{NO}_{2}$ concentration has not shown a clear reducing trend [3]. The Joint Research Centre of the European Commission has identified problems with NOx emissions of diesel vehicles produced under European regulations, being 4 to 7 times higher than the indoor certification standards [4]. Considering that the main emission source of $\mathrm{NO}_{2}$ in metropolises is on-road vehicles, vehicle emission regulations clearly have limited effectiveness. Therefore, it is important to resolve the discrepancy between these emission regulations and actual air pollution [3-5].

To reduce air pollutants, a portable emission measurement system (PEMS) for determining real driving emissions (RDEs) for heavy-duty vehicles was implemented by the United States (U.S.). 
The U.S. Environmental Protection Agency (EPA) discovered a case in which seven heavy-duty vehicle manufacturers manipulated the electronic control system (ECU) software to increase the fuel efficiency of vehicles in high-speed driving conditions and imposed a penalty of approximately 1 billion USD [6]. As a measure to improve the system, the U.S. EPA developed the not-to-exceed (NTE) method, which enforces RDE regulations via a PEMS, and enforced an in-use compliance test for heavy-duty vehicles regarding gaseous substances starting with 2007 models [7,8].

In April 2019, the California Air Resources Board published a paper regarding lowering NOx emissions, which includes three steps. Step 1 (2022-23) involves following the existing Federal Test Procedure (FTP) Ramped Mode Cycle-Supplemental Emissions Test (RMC-SET) and idling standards. Step 2 (2024-26) includes reinforcing the NOx reduction performance at low exhaust temperatures by introducing a low-load test method. Step 3 (2027 and thereafter) regards further strengthening of the NOx standards and test conditions and extending the useful life and warranty periods of engines [9].

In 2003, research in Europe led to the introduction of in-service conformity (ISC) for heavy-duty vehicles using a PEMS. The European Commission Joint Research Centre conducted joint research with the industry and implemented a moving average window analysis method, which they began enforcing in 2013 when the Euro 6 standard was introduced [10,11]. The U.S. NTE method is used to regulate NOx emitted excessively under high-speed, high-load conditions, whereas the RDE test method for heavy-duty vehicles in Europe includes various driving conditions, such as urban road, rural road, and motorways, as targets for regulation [12].

In September 2018, the European Union (EU) expanded the average output window of engines from $20 \%$ or higher for Euro 6 step C to $10 \%$ or higher for Euro 6 step D and expanded the loaded vehicle weight for test vehicles from $50-60 \%$ to $10-90 \%$. In this way, they amended the related regulations to enable tests under various real driving conditions $[12,13]$. Regarding the planned amendment of Euro 6 step $\mathrm{E}$, the EU is considering the inclusion of a particle number $(\mathrm{PN})$ measurement as well as a cold start condition $[14,15]$.

South Korea introduced Europe's RDE test methods and emission allowance standards for light diesel vehicles, which has been implemented simultaneously with the EU. However, heavy-duty diesel vehicles (HDVs) have been introduced emission allowance standards with a time difference of 1-2 years, in contrast to the EU. With respect to the Euro 6 regulations for HDVs, South Korea has introduced Europe's RDE test method by enforcing ISC, which is an RDE test, for vehicles released in or after January 2016. To respond to these RDE regulations, automobile manufacturers are developing various engine technologies and improving the performance of existing aftertreatment systems, such as the diesel oxidation catalyst, diesel particulate filter (DPF), lean NOx trap (LNT), and selective catalytic reduction (SCR) [16-19].

The purpose of this study was to analyze the effects of introducing RDE regulations on HDVs. The NOx emission characteristics of Euro 5 and Euro 6 HDVs that are in use in South Korea were compared. Specifically, the characteristics of NOx emissions, gross vehicle weight (GVW), average vehicle speed, and ambient temperature were analyzed. Notably, NOx emissions were calculated as emissions per unit distance. This unit can be useful for calculating annual emissions of real road driving vehicles in South Korea, using vehicle activity and emission factors [20,21]. In addition, the effectiveness of the introduction of the RDE regulation can be verified by calculating the amount of NOx reduction due to the introduction of the RDE regulation.

\section{Materials and Methods}

\subsection{Test Vehicles and Driving Routes}

The vehicles used for testing were HDVs satisfying the Euro 5 and Euro 6 emission allowance standards with various mileages. The vehicles were classified as categories N2, N3, and M3 according to their GVWs and the European classification method. Test vehicles included 4 Euro 5 and 50 Euro 6 vehicles. A total of $77 \mathrm{RDE}$ tests were performed by repeating the tests on some vehicles. 
Figure 1 shows the test routes for the RDE of Euro 6 heavy-duty vehicles. The measurements for Euro 5 were made while driving general roads instead of a given driving route. The driving routes shown in Figure 1 were divided into route A and route B, which consist of general roads passing through Incheon, Seoul, and Paju in South Korea. Seoul is the capital city of Korea, and Paju and Incheon are the cities near Seoul. Route A is the test-driving route, consisting of urban roads ( $45 \%)$, rural roads ( $25 \%)$, and motorways ( $30 \%$ ) for the N2 and M3 categories. Route B is a test-driving route consisting of urban roads (20\%), rural roads $(25 \%)$, and motorways $(55 \%)$ for the N3 category. The trip shares for Euro 5 and Euro 6 vehicles are listed in Table 1. The trip shares of the test vehicles were less than $50 \mathrm{~km} / \mathrm{h}$ for urban roads, $50-75 \mathrm{~km} / \mathrm{h}$ for rural roads, and $75 \mathrm{~km} / \mathrm{h}$ or higher for motorways, with an error range of $\pm 5 \%$. The Euro 5 test vehicles for RDE were meant for testing before the implementation of the ISC test regulation in Korea (enforcement was initiated in 2016). Therefore, there were differences among the urban road, rural road, and motorway ratios with Euro 6 vehicles tested according to the ISC test regulations. The fuel used was the diesel fuel typical in Korean petrol stations with less than 5 ppm sulfur. Despite the $10 \mathrm{ppm}$ manufacturing standards, refineries voluntarily supply high-quality automotive fuel with a sulfur content of $4-5 \mathrm{ppm}$.
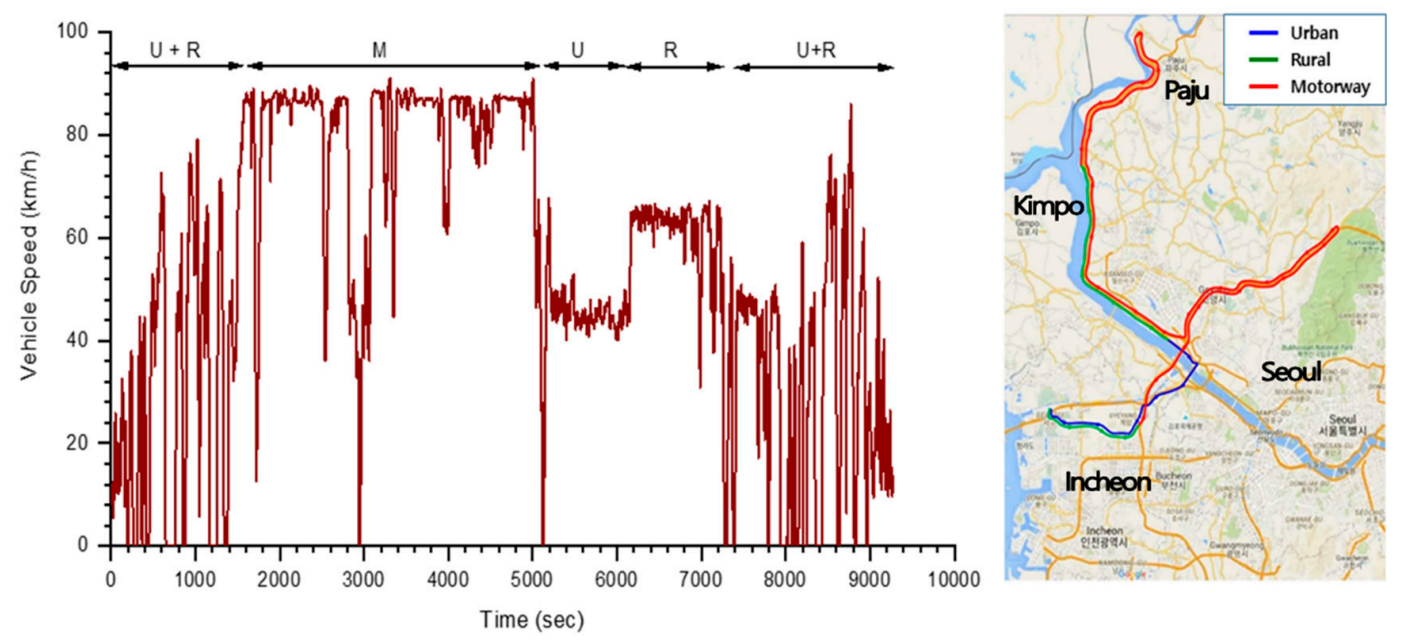

(a)
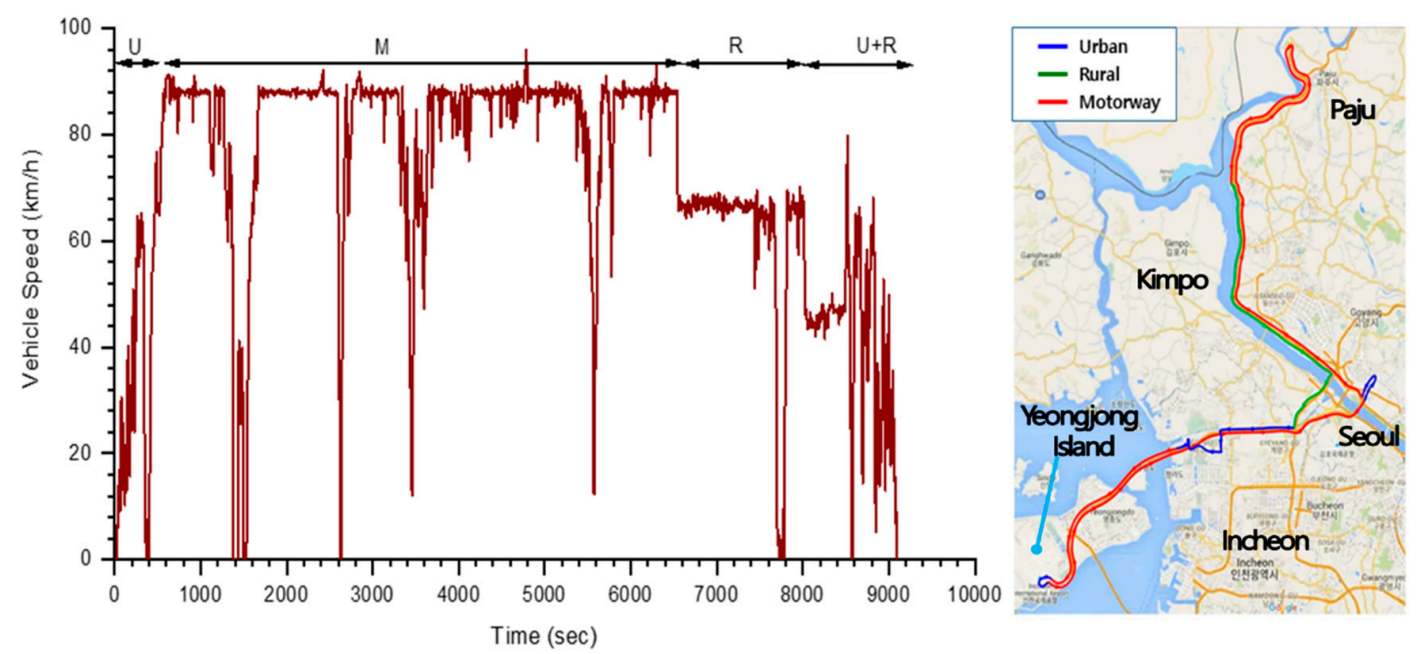

(b)

Figure 1. Real driving emission (RDE) test routes for heavy-duty vehicles. (a) RDE test route A for trucks with gross vehicle weights (GVWs) less than 12 tons; urban (U): $45 \%$, rural (R): $25 \%$, motorway (M): 30\%. (b) RDE test route B for trucks with GVWs more than 12 tons and buses; urban (U): $20 \%$, rural (R): $25 \%$, motorway (M): $55 \%$. 
Table 1. Specifications of tested heavy-duty diesel vehicles.

\begin{tabular}{|c|c|c|c|c|c|}
\hline Emission Regulations & Vehicle Category & $\begin{array}{l}\text { Gross Vehicle } \\
\text { Weight (Ton) }\end{array}$ & Driving Work & $\begin{array}{l}\text { Driving Route } \\
\text { (Trip Shares) }\end{array}$ & Test Number \\
\hline \multirow{4}{*}{ Euro 5} & \multirow{2}{*}{ N2 } & 7 & \multirow{4}{*}{$\mathrm{ETC} \times 3$} & \multirow{2}{*}{ (U 4:R 3:M 3) } & 2 \\
\hline & & 10 & & & 4 \\
\hline & N3 & 33 & & (U 3:R 2:M 5) & 4 \\
\hline & M3 & 12 & & (U 4:R 3:M 3) & 2 \\
\hline \multirow{3}{*}{ Euro 6 step C } & N2 & $3.5-7$ & \multirow{3}{*}{ WHTC $\times 5$} & route A (U 4.5:R 2.5:M 3.0) & 13 \\
\hline & N3 & $7-40$ & & \multirow{2}{*}{ route B (U 2.0:R 2.5:M 5.5) } & 48 \\
\hline & M3 & $12-16$ & & & 4 \\
\hline
\end{tabular}

ETC: European Transient Cycle; WHTC: World Harmonized Transient Cycle; U: urban; R: rural; M: motorway; category N2(truck): a maximum mass exceeding 3.5 tons but not exceeding 12 tons; category N3(truck): a maximum mass exceeding 12 tons; category M3(bus): a maximum mass exceeding 5 tons.

The RDE test conditions consisted of $82.5 \mathrm{kPa}$ or higher atmospheric pressure and $5-37{ }^{\circ} \mathrm{C}$ ambient temperature. Loaded vehicle weight was configured to be $50-60 \%$ of the maximum proper freight weight. The road driving time for Euro 6 vehicles was set on the basis of a driving work of approximately five times the work of the World Harmonized Vehicle Cycle (WHTC), which was the certification test mode. The road driving time for Euro 5 vehicles was set on the basis of a driving work of approximately three times the work of the European Transient Cycle (ETC), which was the certification test mode, taking 3-3.5 h. The work of three times the ETC of Euro 5 is known to be equivalent to the work of five times the WHTC of Euro $6[10,22]$.

\subsection{On-Road Emission Test Equipment}

During the RDE test for Euro 6 vehicles, the air pollutants were measured using a Semtech-ECOSTAR gas analyzer, which consists of an exhaust flow meter (EFM) for measuring the flow rate of the exhaust gas; devices for measuring gaseous substances, including non-dispersive infrared (NDIR) detection for $\mathrm{CO}_{2}$, non-dispersive ultraviolet (NDUV) for $\mathrm{CO}$ and $\mathrm{NOx}$, and a flame ionization detector (FID) for total hydrocarbons (THC); and a power distribution control module, which maintains constant flow rates and temperatures of the sampling gases. Each vehicle was equipped with a controller area network (CAN) communication system for acquiring data such as the engine output from the ECU; a global positioning system (GPS) for checking environmental conditions for driving; and temperature, pressure, humidity, and altitude sensors. The PEMS equipment was installed as shown in Figure 2.

An OBS-2200 gas analyzer was used for Euro 5 vehicle tests, consisting of a volume flow meter, power supply unit, power control unit, external input unit, GPS, and gas concentration analyzer. The gas concentration analyzer measures $\mathrm{CO}_{2}, \mathrm{CO}, \mathrm{THC}$, and $\mathrm{NOx}$ concentrations in $1 \mathrm{~Hz}$ cycles. To convert the measured concentrations into masses, the exhaust gas volume flow rate is required. Thus, the exhaust gas volume flow rate was measured using a Pitot tube flow meter [23]. The measured flow rate was converted to a value of the standard condition using the temperature and pressure of the exhaust gas. The performance of the PEMS was verified in accordance with CFR 1065, which is the U.S. federal engine testing standard. The pollutant emission measurement results of the PEMS were compared with the chassis dynamometer measurement results, and no statistically significant differences were observed between the two [24,25]. Table 2 lists the specifications of the PEMS used for RDE testing of the Euro 5 and Euro 6 vehicles. 


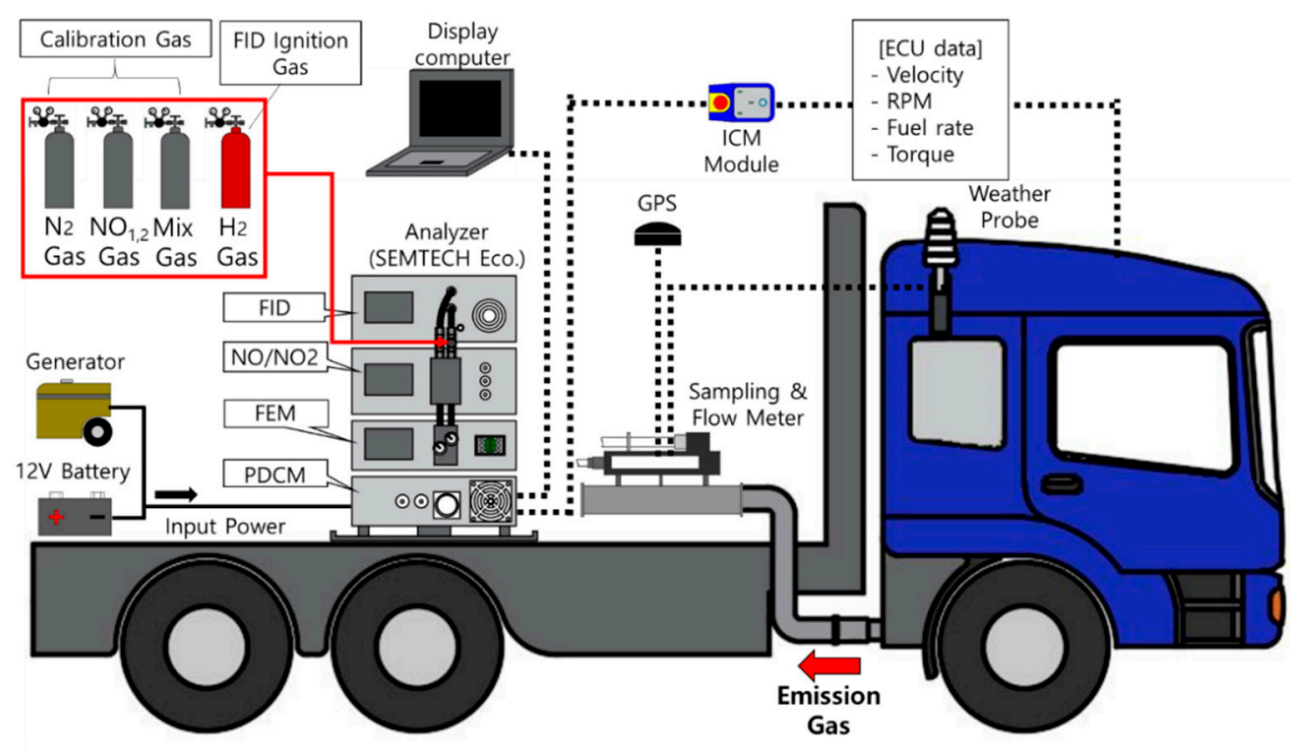

Figure 2. Schematic diagram of the experimental setup for Euro 6 heavy-duty vehicles (Euro 5 vehicles used a Horiba OBS-2200 analyzer). FID: flame ionization detector, ECU: electronic control system, FEM: fuel economy meter, GPS: global positioning system, ICM: in-vehicle control module, PDCM: power distribution and control module.

Table 2. Characteristics of portable emission measurement system (PEMS) analyzers.

\begin{tabular}{ccc}
\hline Gas Analyzers & Euro 6 Vehicles & Euro 5 Vehicles \\
\hline Manufacturer & Sensors Inc. & Horiba \\
Model & Semtech-ECOSTAR & OBS-2200 \\
CO (Measuring range) & NDUV $(0-8$ vol\% $)$ & NDIR $(0-10 \mathrm{vol} \%)$ \\
THC (Measuring range) & FID $(0-30,000 \mathrm{ppm} \mathrm{C)}$ & FID $(0-10,000 \mathrm{ppm} \mathrm{C)}$ \\
NOx (Measuring range) & NDUV $(0-3000 \mathrm{ppm})$ & CLD $(0-3000 \mathrm{ppm})$ \\
Exhaust flow & EFM4 (Pitot flow meter $)$ & Volume sampler \\
\hline
\end{tabular}

NDIR: Non-dispersive infrared detection; CLD: chemiluminescence detection; NDUV: non-dispersive ultraviolet; FID: flame ionization detector; EFM: exhaust flow meter; THC: total hydrocarbons; NOx: nitrogen oxide.

\subsection{Data Analysis}

The moving average window (MAW) analysis method, which is the calculation method for the RDE test in Europe, was used to calculate the value corresponding to the 90 percentiles. The emissions for HDVs are regulated by the average emissions per engine work; however, $1 \mathrm{~km}$ unit sections were set to compare the pollutants emitted during the real driving of Euro 5 and Euro 6 vehicles. The data were analyzed by classifying the emissions at average vehicle speeds in $10 \mathrm{~km} / \mathrm{h}$ increments within each section $[21,26]$.

\section{Results and Discussion}

\subsection{Euro 5 and Euro 6 Vehicle Emissions}

The vehicles used in the RDE test were heavy-duty trucks and buses, and the loaded vehicle weight generally increased with GVW. The loaded vehicle weight of the test vehicles was set to $50-60 \%$ of the maximum loaded vehicle weight. Figure 3 shows the RDE measurement results (CO, THC, NOx) of HDVs. The mileage of the vehicles used for this test was about 50,000 to 300,000 km. Thus, due to aging, their air pollutant emissions recorded during the test period could be higher than at the time they were certified. The $\mathrm{CO}$ and THC emissions satisfied the indoor emission allowance standards in real driving conditions on the road. The NOx emissions allowance standards of ISC for HDVs in South Korea was $0.92 \mathrm{~g} / \mathrm{kWh}$ from 2016 to 2017, which is twice the engine test standard (WHTC: $0.46 \mathrm{~g} / \mathrm{kWh}$ ), 
and was revised to $0.69 \mathrm{~g} / \mathrm{kWh}$ in 2017 [27]. Herein, NOx emissions from some models exceeded the standards. Compared with the Euro 5 HDVs, NOx emissions from these vehicles decreased by approximately $89 \%[28,29]$.

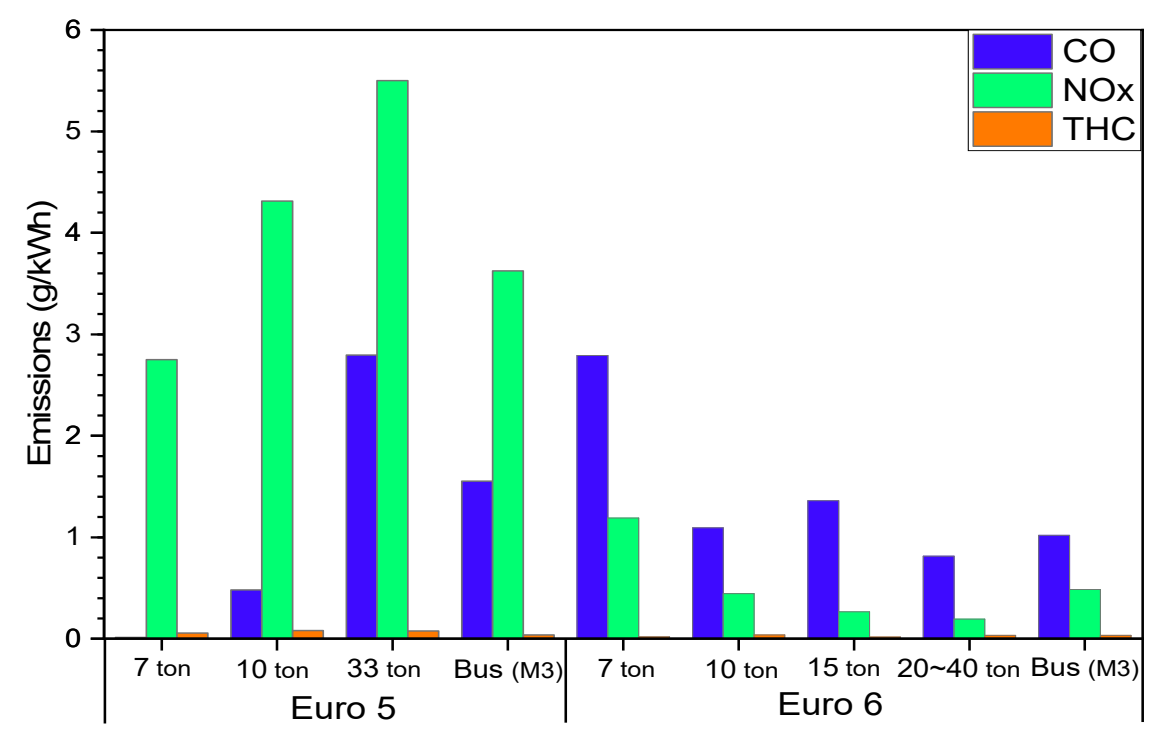

Figure 3. Specific on-road emissions from Euro 6 heavy-duty vehicles in comparison with Euro 5 tested vehicles of trucks and buses. Vehicles are categorized on the basis of their GVWs.

The larger the GVW, the higher the NOx emissions from Euro 5 HDVs on all road types; however, the Euro 6 HDVs showed extremely low NOx emissions despite their high GVWs. Thus, the NOx emissions from Euro $6 \mathrm{HDVs}$ with $\geq 10$ ton GVWs significantly improved compared to those from Euro 5 HDVs. Furthermore, Euro 6 HDVs generally showed relatively low NOx emissions regardless of GVW [30].

\subsection{Driving Distance and Gross Vehicle Weight}

Figure 4 shows the real driving condition NOx emissions per driving distance $(\mathrm{g} / \mathrm{km})$ for the Euro 5 and Euro 6 test vehicles. Even though the emissions per driving distance are different from those in the certification standard unit of heavy-duty vehicles, these are more direct in terms of evaluating the actual contribution of vehicle exhaust gases to air pollution. The average real driving condition NOx emissions from Euro $6 \mathrm{HDVs}$ was $0.310 \mathrm{~g} / \mathrm{km}$, which is approximately $88.5 \%$ lower than the $2.692 \mathrm{~g} / \mathrm{km}$ of the Euro 5 HDVs. The Euro 5 diesel vehicles with higher GVWs showed higher NOx emissions, but the Euro 6 vehicles showed generally low NOx emissions, regardless of GVW [30]. The reason for this observation can be attributed to the technological improvement of the engine and aftertreatment system in response to RDE regulations [16-19]. 


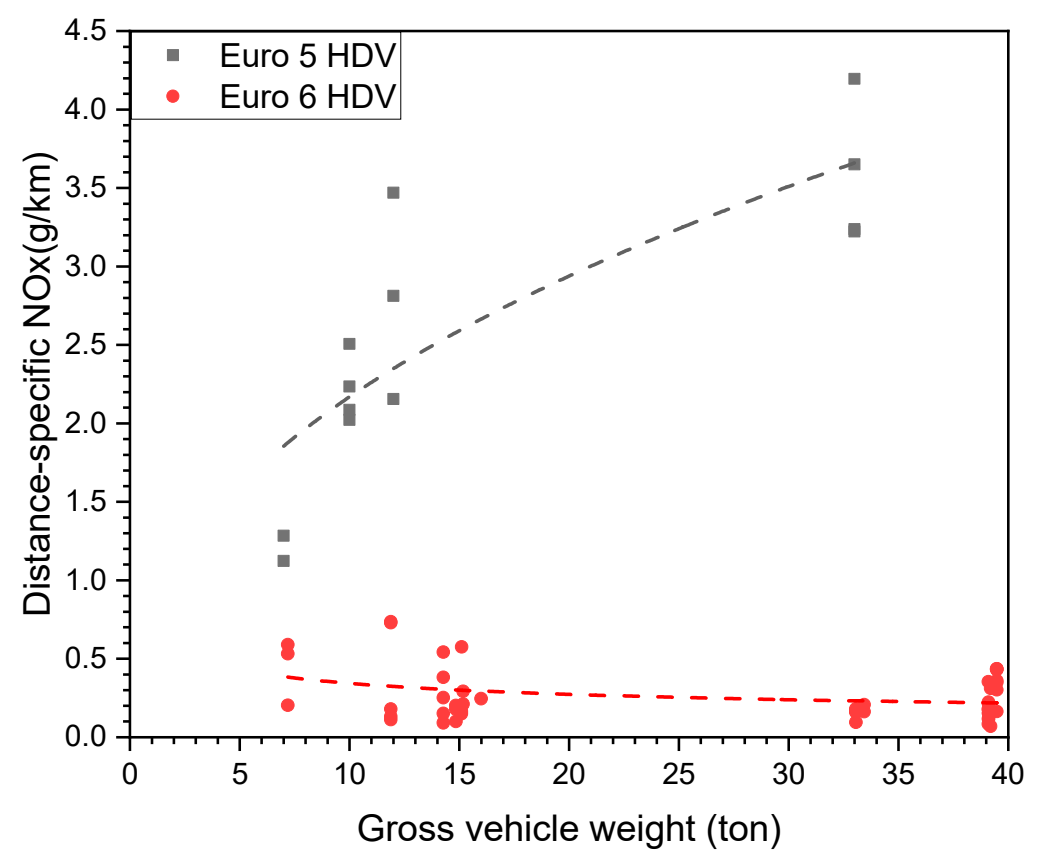

Figure 4. On-road NOx emissions from Euro 5 and Euro 6 heavy-duty diesel vehicles (HDVs) as a function of GVW.

\subsection{Average Vehicle Speed and Gross Vehicle Weight}

Figure 5 shows a comparison of NOx emission characteristics under various average vehicle speed conditions between Euro 5 and Euro 6 HDVs. Data analysis was performed for trucks with 7 and 10 tons of GVW using the $1 \mathrm{~km}$ average window method. As verified by the characteristics of the road types, it was found that the NOx emissions decreased under all driving conditions due to the application of the Euro 6 regulations. The trucks with a GVW of 10 tons had a higher NOx reduction effect than the trucks with a GVW of 7 tons did. In particular, the NOx emissions from the 10 ton trucks decreased to approximately $90 \%$ of the Euro 5 level under urban driving conditions of less than $40 \mathrm{~km} / \mathrm{h}[30]$.

Figure 6 shows the NOx emissions under various average vehicle speed conditions for Euro 6 HDVs. The NOx emissions from trucks with GVWs of 15 and 40 tons were lower than those of trucks with GVWs of 7 and 10 tons at all the average speed ranges. The trucks and large buses with GVWs of 40 tons or higher, which were often driven under high-speed conditions, showed no significant differences compared to the 7-15-ton trucks. SCR systems applied to Euro 6 HDV can maintain low levels of NOx emissions regardless of GVW due to the improved low temperature performance of SCR catalysts and the insulation of exhaust lines [31,32]. The current vehicle emission factors were calculated as a function of the average vehicle speed by driving in various modes separately from the certification test mode in the chassis dynamometer. Figure 6 shows the RDE results determined through the $1 \mathrm{~km}$ average window analysis method, which can be sufficiently expressed in the form of current vehicle emission factors. Furthermore, as they consider real driving on urban roads, rural roads, and motorways in the Seoul Metropolitan Area, they can reflect the realistic conditions in a more effective manner. It is expected that reliability and reality could be enhanced by using enormous quantities of real driving test results for emission factor calculations [21,33]. 


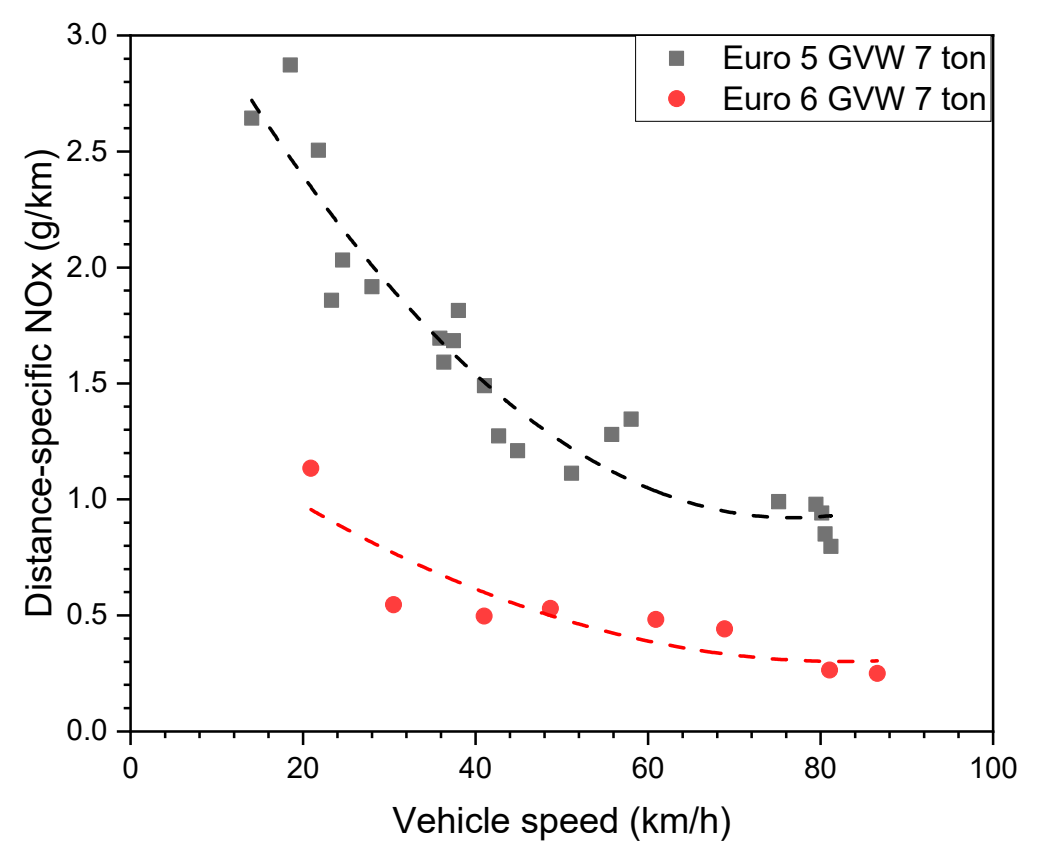

(a)

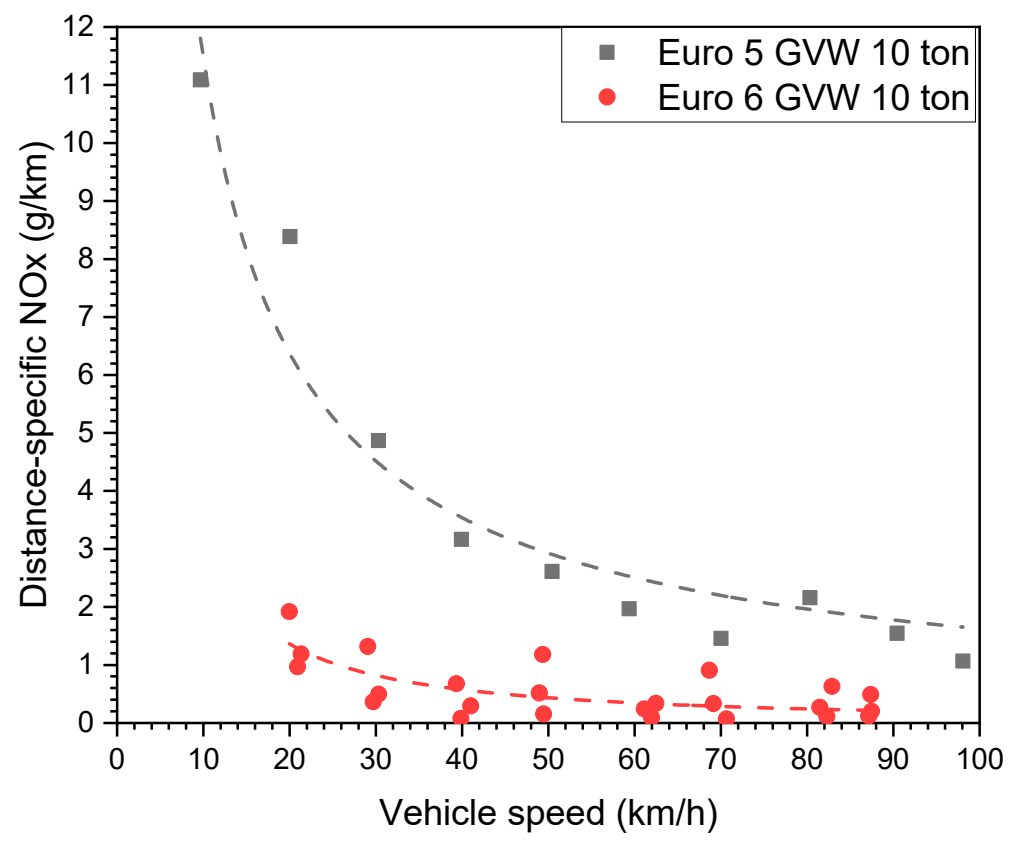

(b)

Figure 5. On-road NOx emissions from Euro 5 and Euro 6 HDVs relative to the average vehicle speed. (a) 7 ton GVW truck; (b) 10 ton GVW truck. 


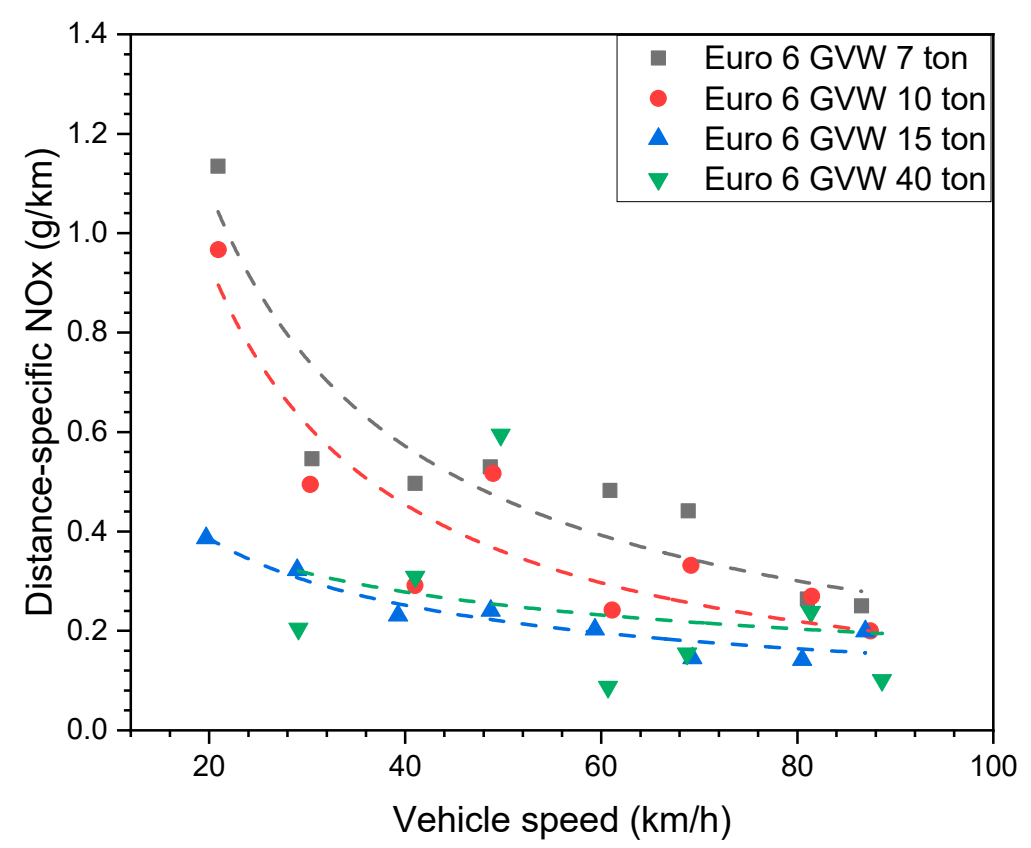

Figure 6. On-road NOx emissions from Euro $6 \mathrm{HDVs}$ as a function of the average vehicle speed.

\subsection{Ambient Temperature}

Figure 7 shows the real driving condition NOx emission characteristics of Euro 6 HDVs as a function of the ambient temperature. During the testing period, the ambient temperature ranged from 5 to $37^{\circ} \mathrm{C}$. Some N2 category vehicles with a GVW of 7 tons or less showed high NOx emissions at an ambient temperature of $30-37^{\circ} \mathrm{C}$. The NOx emissions in the range of $30-35^{\circ} \mathrm{C}$ were slightly higher than in the normal test temperature range $\left(15-25^{\circ} \mathrm{C}\right)$. Although the number of measured vehicles was insufficient, the NOx emissions at $5-10{ }^{\circ} \mathrm{C}$ were slightly higher than at normal test temperatures $\left(15-25^{\circ} \mathrm{C}\right)[33,34]$.

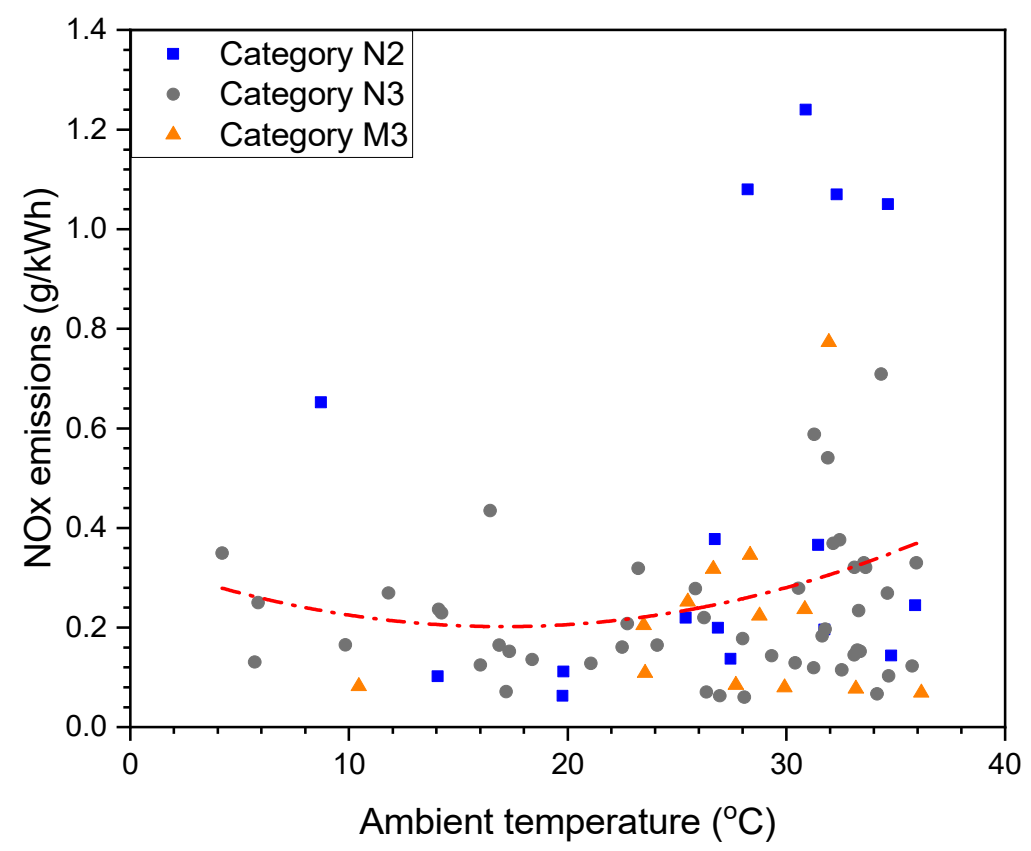

Figure 7. On-road NOx emissions from Euro 6 heavy-duty vehicles relative to the ambient temperature. 
As is evident from Figure 7, NOx emissions were found to be high when the temperatures were less than $10^{\circ} \mathrm{C}$ and when these were higher than $30^{\circ} \mathrm{C}$. Low temperatures were found to have no significant effect on NOx emissions because most HDVs have insulated exhaust pipes; the temperature of the exhaust gas did not fall below the activation temperature of the catalyst under the influence of the external environment. Increasing the utilization rate of the exhaust gas recirculation apparatus at an ambient temperature of $30^{\circ} \mathrm{C}$ or higher may cause high temperature exhaust gases to enter the combustion chamber, resulting in unstable combustion of the engine. In these cases, manufacturers usually reduce the EGR rate to protect the engine [19]. However, as shown in Figure 7, most vehicles showed significantly lower values than the emission allowance standards at high temperatures, except for select models. Therefore, even at low or high ambient temperatures, aftertreatment devices, such as SCR devices, can sufficiently reduce NOx emissions. Various test results are needed to confirm the correlation with the ambient temperature. In Korea, the ISC regulation of HDVs has been in effect since 2016, and the Euro 5 HDV was not subject to ISC regulation. Most Euro 5 HDVs in use in Korea are currently out of their warranty periods, and finding ISC target vehicles is a challenge [27]. Due to this reason, there are fewer tests conducted for Euro 5 HDVs. The number of test vehicles cannot be used as a representative value as there are very few test vehicles, and therefore only Euro 6 vehicles are considered. For this reason, the Euro $5 \mathrm{HDV}$ is not included in Figure 7, as the data of ISC test results of Euro $5 \mathrm{HDV}$ is insufficient.

\section{Conclusions}

In this study, air pollutants emitted during on-road driving of Euro 5 and Euro 6 HDVs were compared. To reduce excessive NOx emissions from these vehicles under real driving conditions, the effect of an RDE management system was studied. The conclusions of this study can be summarized as follows:

- HDVs produced after the introduction of the Euro 6 emission allowance standards and RDE management system generally satisfied the real driving emission allowance standard. Compared with the Euro 5 HDVs, NOx emissions from these vehicles decreased by approximately $89 \%$. The RDE average NOx emissions for the Euro $6 \mathrm{HDV}$ s were lower than the RDE average for light-duty diesel vehicles (Euro 6b, $0.56 \mathrm{~g} / \mathrm{km}$ ) [16,35].

- NOx emissions from Euro 5 HDVs increased with increasing GVW; however, Euro 6 HDVs showed low NOx emissions regardless of the GVW.

- NOx emissions from both Euro 5 and Euro 6 HDVs increased with a decrease in the average vehicle speed. NOx emissions from HDVs weighing 15 and 40 tons were lower than those from vehicles, weighing 7 and 10 tons on average.

- The introduction of emission allowance standards reduced the difference in NOx emissions from indoor certification tests and real road driving, thereby it will be expected to reduce the NOx emissions in the transport sector.

To reflect real road driving characteristics more broadly in the RDE test method for heavy-duty vehicles, it is necessary to consider engine power, which is a criterion for classifying effective sections, in the MAW analysis method, as well as including cold start conditions. Application of these suggestions could improve NOx emissions under low-speed urban driving conditions.

Author Contributions: Conceptualization, J.P. and S.K.; methodology, J.P. and S.K.; formal analysis, J.P. and S.K.; data curation, J.L. (Jongchul Lee), H.K., G.K., J.L. (Jongtae Lee), J.K.; writing—original draft preparation, J.P., S.K.; writing-review and editing, H.K., J.L. (Jongtae Lee). All authors have read and agreed to the published version of the manuscript.

Funding: This research was funded by the National Institute of Environmental Research (NIER) (grant number NIER-2017-01-01-076), affiliated with the Ministry of the Environment of the Republic of Korea (Korean MOE).

Acknowledgments: We thank the dedicated personnel at the National Institute of Environmental Research (NIER) testing laboratory for all their assistance. 
Conflicts of Interest: The authors declare no conflict of interest.

\section{References}

1. Wagner, W.; Rutherford, D. Survey of Best Practices in Emission Control of In-Use Heavy-Duty Diesel Vehicles; International Council Clean Transportation (ICCT) Report; ICCT: Washington, DC, USA, 2013.

2. Air Environment Information Center, City of Seoul, Korea. Available online: http://cleanair.seoul.go.kr (accessed on 10 November 2019).

3. WHO. Global Ambient Air Quality Database (Update 2018). Available online: https://www.who.int/ airpollution/data/cities/en/ (accessed on 9 November 2019).

4. Weiss, M.; Bonnel, P.; Hummel, R.; Manfredi, U.; Colombo, R.; Lanappe, G.; le Lijour, P.; Sculati, M. Analyzing On-Road Emissions of Light-Duty Vehicles with Portable Emission Measurement Systems (PEMS); Joint Research Centre: Ispra, Italy, 2011; ISBN 978-92-79-19072-8. Available online: https://publications.jrc.ec.europa.eu/ repository/handle/JRC62639 (accessed on 30 December 2019).

5. European Environmental Agency. Air Quality in Europe 2018; EEA: Copenhagen, Denmark, 2018.

6. US EPA; DOJ. EPA Announce One-Billion-Dollar Settlement with Diesel Engine Industry for Clean Air Violations. News Release, 22 October 1998. Available online: https://archive.epa.gov/epapages/newsroom_ archive/newsreleases/93e9e651adeed6b7852566a60069ad2e.html (accessed on 10 November 2016).

7. US EPA. Control of Emissions of Air Pollution from New Motor Vehicles: In-Use Testing for Heavy-Duty Diesel Engines and Vehicles. Federal Register. 2005. Available online: https://www.federalregister.gov/documents/2005/06/14/05-11470/control-of-emissions-of-air-pollutionfrom-new-motor-vehicles-in-use-testing-for-heavy-duty-diesel (accessed on 9 December 2019).

8. Code of Federal Regulations. Title 40: Protection of Environment, Part 86, 86.007-11, Emission Standards and Supplemental Requirements for 2007 and Later Model Year Diesel Heavy-Duty Engines and Vehicles. Available online: https://www.govinfo.gov/app/details/CFR-2010-title40-vol18/CFR-2010-title40-vol18sec86-007-11 (accessed on 10 November 2019).

9. Prepared by Staff of the Mobile Source Control Division Mobile Source Regulatory Development Branch. California Air Resources Board, Staff White Paper. Available online: https:/ww3.arb.ca.gov/msprog/ hdlownox/white_paper_04182019a.pdf (accessed on 9 December 2019).

10. Bonnel, P.; Kubelt, J.; Provenza, A. Heavy-duty Engines Conformity Testing Based on PEMS; Publications Office of the European Union: Ispra, Italy, 2014; Available online: https://publications.jrc.ec.europa.eu/repository/ handle/JRC62639 (accessed on 30 December 2019).

11. Commission Regulation (EU) No 582/2011. Implementing and Amending Regulation (EC) No 595/2009 of the European Parliament and of the Council with Respect to Emissions from Heavy Duty Vehicles (EURO VI) and Amending Annexes I and III to Directive 2007/46/EC of the European Parliament and of the Council, 25 June 2011. Available online: https://eur-lex.europa.eu/eli/reg/2011/582/oj (accessed on 10 November 2017).

12. European Commission. Commission Regulation (EU) 2018/932 of 29 June 2018 amending Regulation (EU) No 582/2011 as regards the provisions on testing by means of portable emission measurement systems (PEMS) and the requirements for universal fuel range type-approval. Off. J. Eur. Union 2018, L165, 32-34.

13. Commission Regulation (EU) 2016/1718, Amending Regulation (EU) No 582/2011 with Respect to Emissions from Heavy-Duty Vehicles as Regards the Provisions on Testing by Means of Portable Emission Measurement Systems (PEMS) and the Procedure for the Testing of the Durability of Replacement Pollution Control Devices, 9 September 2016. Available online: https://eur-lex.europa.eu/legal-content/en/TXT/?uri=CELEX\% 3A32016R1718 (accessed on 8 November 2019).

14. Mendoza-Villafuerte, P.; Suarez-Bertoa, R.; Giechaskiel, B.; Riccobono, F.; Bulgheroni, C.; Astorga, C.; Perujo, A. NOx, $\mathrm{NH}_{3}, \mathrm{~N}_{2} \mathrm{O}$ and $\mathrm{PN}$ real driving emissions from a Euro VI heavy-duty vehicle. Impact of regulatory on-road test conditions on emissions. Sci. Total Environ. 2017, 609, 546-555. [CrossRef] [PubMed]

15. Giechaskiel, B.; Lähde, T.; Suarez-Bertoa, R.; Clairotte, M.; Grigoratos, T.; Zardini, A.; Perujo, A.; Martini, G. Particle number measurements in the European legislation and future JRC activities. Combust. Engines 2018, 174, 3-16. 
16. Cha, J.; Lee, J.; Chon, M. Evaluation of real driving emissions for Euro 6 light-duty diesel vehicles equipped with LNT and SCR on domestic sales in Korea. Atmos. Environ. 2019, 196, 133-142. [CrossRef]

17. Jiang, Y.; Yang, J.; Cocker, D., III; Karavalakis, G.; Johnson, K.C.; Durbin, T.D. Characterizing emission rates of regulated pollutants from model year 2012+ heavy-duty diesel vehicles equipped with DPF and SCR systems. Sci. Total Environ. 2018, 619, 765-771. [CrossRef] [PubMed]

18. Kang, W.; Choi, B.; Jung, S.; Park, S. PM and NOx reduction characteristics of LNT/DPF+SCR/DPF hybrid system. Energy 2018, 143, 439-447. [CrossRef]

19. Kim, S.; Choi, S.; Jin, H. Pressure model based coordinated control of VGT and dual-loop EGR in a diesel engine air-path system. Int. J. Automot. Technol. 2016, 17, 193-203. [CrossRef]

20. Park, G.; Mun, S.; Hong, H.; Chung, T.; Jung, S.; Kim, S.; Seo, S.; Kim, J.; Lee, J.; Kim, K.; et al. Characterization of Emission Factors Concerning Gasoline, LPG, and Diesel Vehicles via Transient Chassis-Dynamometer Tests. Appl. Sci. 2019, 9, 1573. [CrossRef]

21. Lee, T.; Shin, M.; Lee, B.; Chung, J.; Kim, D.; Keel, J.; Lee, S.; Kim, I.; Hong, Y. Rethinking NOx emission factors considering on-road driving with malfunctioning emission control systems: A case study of Korean Euro 4 light-duty diesel vehicles. Atmos. Environ. 2019, 202, 212-222. [CrossRef]

22. Verbeek, R.; Ligterink, N.; Dekker, H. Correlation Factors between European and World Harmonised Test Cycles for Heavy-Duty Engines. TNO Science and Industry 2008. Available online: http: //www.donnainaffari.it/wp-content/uploads/2013/01/Rapporto-armonizzazione-industria-mondiale.pdf (accessed on 30 December 2019).

23. Akard, M.; Oestergaard, K.; Porter, S.; Gautam, M.; Carder, D.; Love, D.; Moye, T.; Garabedian, H. Further Investigation into the Performance of Two Different On-Board Emission Measurement System Compared to Laboratory Measurement; SAE Technical Paper, 2004-01-3480; Society of Automotive Engineers, Inc.: Detroit, MI, USA, 2004.

24. Lee, T.; Keel, J.; Park, J.; Park, Y.; Hong, J.; Lee, D. Speed-based emission factor regarding vehicle specific power and acceleration during on-road driving. Trans. Korean Soc. Automot. Eng. 2011, 19, 73-81. (In Korean with English Abstract)

25. Nakamura, H.; Akard, M.; Porter, S.; Kihara, N.; Adachi, M.; Khalek, I. Performance Test Results of a New On-Board Gaseous Emission Measurement System Conformed with CFR Part 1065; SAE Technical Paper, 2007-01-1326; Society of Automotive Engineers, Inc.: Detroit, MI, USA, 2007.

26. Giechaskiel, B. Solid particle number emission factors of Euro VI heavy-duty vehicles on the road and in the laboratory. Int. J. Environ. Res. Public Health 2018, 15, 304. [CrossRef] [PubMed]

27. Korea Ministry of Environment. Clean Air Conservation ACT. 2017. Available online: http://www.law.go.kr/ LSW/eng/engLsSc.do?menuId=2\&query=clean\%20air\#liBgcolor0 (accessed on 8 November 2019).

28. Feist, M.; Sharp, C.; Spears, M. Determination of PEMS measurement allowances for gaseous emissions regulated under the heavy-duty diesel engine in-use testing program. Part 1-Project overview and PEMS evaluation procedures. SAE Int. J. Fuels Lubr. 2009, 2, 435-454. [CrossRef]

29. Grigoratos, T.; Fontaras, G.; Giechaskiel, B.; Zacharof, N. Real world emissions performance of heavy-duty Euro VI diesel vehicles. Atmos. Environ. 2019, 201, 348-359. [CrossRef]

30. Frey, H.; Rouphail, N.; Zhai, H. Link-Based Emission Factors for Heavy-Duty Diesel Trucks Based on Real-World Data. Transp. Res. Rec. 2008, 2058, 23-32. [CrossRef]

31. Han, J.; Kim, T.; Jung, H.; Pyo, S.; Cho, G.; Oh, Y.; Kim, H. Improvement of NOx reduction rate of urea SCR system applied for a Non-road diesel engine. Int. J. Automot. Technol. 2019, 20, 1153-1160. [CrossRef]

32. Gao, F.; Tang, X.; Yi, H.; Zhao, S.; Li, C.; Li, J.; Shi, Y.; Meng, X. A Review on Selective Catalytic Reduction of NOx by NH3 over Mn-Based Catalysts at Low Temperatures: Catalysts, Mechanisms, Kinetics and DFT Calculations. Catalysts 2017, 7, 199. [CrossRef]

33. Xin, W.; Guohua, S.; Yizheng, W.; Lei, Y.; Zhiqiang, Z. A NOx Emission Model Incorporating Temperature for Heavy-Duty Diesel Vehicles with Urea-SCR Systems Based on Field Operating Modes. Atmosphere 2019, 10, 337. [CrossRef] 
34. Yadav, D.; Kavaiya, A.R.; Mohan, D.; Prasad, R. Low Temperature Selective Catalytic Reduction (SCR) of $\mathrm{NOx}$ Emissions by Mn-Doped $\mathrm{Cu} / \mathrm{Al}_{2} \mathrm{O}_{3}$. Bull. Chem. React. Eng. Catal. 2017, 12, 415-429. [CrossRef]

35. Cha, J.; Yu, Y.S.; Lee, D.; Chon, M.S. RDE Characteristics of Euro 6 Light Duty Diesel Vehicles Regarding to Driving Conditions. J. ILASS-Korea 2017, 22, 218-224.

(C) 2020 by the authors. Licensee MDPI, Basel, Switzerland. This article is an open access article distributed under the terms and conditions of the Creative Commons Attribution (CC BY) license (http://creativecommons.org/licenses/by/4.0/). 